\title{
LA TEORÍA DE LA VERDAD EN HABERMAS
}

MANUEl COMESAÑA

Universidad Nacional de Mar del Plata

SOCIEDAD ARGENTINA DE INVESTIGACIONES FILOSÓFICAS

Me parece conveniente comenzar el análisis de las ideas de Habermas sobre la verdad con una aclaración preliminar de carácter "metodológico". Mi primera "hipótesis de trabajo" para un examen crítico de la teoría habermasiana de la verdad es ad hominem: en 1980, ocho años después de haber publicado un artículo sobre el tema, Habermas, al tratar de responder a ciertas objeciones, se da cuenta de que dicha teoría es floja y no sabe cómo arreglarla, a raíz de lo cual reiteradamente promete hacerlo en un futuro indeterminado, como se ve en estos dos pasajes - a los que podrían agregarse otros-:

El artículo del año 1972 en que desarrollé mi tesis ha tenido una viva resonancia. Hubo una serie de objeciones que me impresionaron tanto, que tengo en proyecto proceder a una réplica detallada y algo prolija. En la presente ocasión no puedo pretender anticiparla con pocas palabras. [1980, p. 464]

El artículo sobre "Teorías de la verdad" provocó una viva discusión, en la que me percaté de que esta teoría discursiva de la verdad, inspirada en Ch.S. Pierce, ha menester aún una cuidadosa elaboración. [1984, p. 15]

Parecería que, en algunas ocasiones, la advertencia de que una teoría tiene carácter preliminar, tentativo, programático, debe ser tenida en cuenta en su examen crítico para evitar que teorías potencialmente meritorias perezcan a causa de enfermedades infantiles. Pero este "principio de caridad" no puede ser aplicado de modo irrestricto; en particular, no puede ser admitido como estratagema de inmunización a favor de una teoría publicada hace muchos años, sobre todo si se trata de una teoria filosófica, que no necesita esperar cosas como la realización de observaciones o experimentos hasta ahora tecnológicamente imposibles. Las afirmaciones que Habermas haga en el futuro sobre la verdad las podremos discutir cuando existan; por ahora no tenemos más remedio que considerar exclusivamente las que ya hizo. 
Cuando "verdadero" se aplica a una parte de lo que decimos - y no, por ejemplo, a personas, según se hace al decir "Fulano es un verdadero amigo"-, la verdad plantea tres problemas filosóficos: $a$ ) icuáles son las cosas que son verdaderas o falsas?; $b$ ) ¿qué tiene que pasar para que una de esas cosas sea verdadera?; c) icómo se averigua si lo es? El problema a) pregunta por los "portadores de la verdad"; 1 b) por la definición de la verdad, y c), por un criterio de verdad. Analizaremos críticamente las ideas de Habermas sobre la verdad examinando sus respuestas a esas tres preguntas, tales como aparecen en su artículo de 1972 y en su "Réplica a objeciones", de 1980. Comenzaremos por el primero de estos problemas. Los candidatos habituales a portadores de verdad ${ }^{2}$ son las oraciones, las afirmaciones, las proposiciones y las creencias. Varios autores han sostenido que los portadores de verdad no pueden ser las oraciones. Uno de los argumentos que se presentan en apoyo de esta tesis es que si las oraciones fueran verdaderas o falsas, algunas oraciones serían a veces verdaderas y a veces falsas; otro es que algunas oraciones, por ejemplo las imperativas, no son ni verdaderas ni falsas. Como señala Haack (1978, pp. 100-101), estos argumentos no parecen concluyentes, pero sugieren que, sean cuales fueren las cosas que se elijan como portadores de verdad, deberían satisfacer dos desiderata: 1) que su valor de verdad no cambie; 2) que todos los miembros de la clase pertinente sean verdaderos o falsos.

1 Platts, 1979, se declara incapaz de "discernir aquí un problema bien definido y sustancial" (p. 63). Pero en Platts, 1985, sostiene que esto es así solo cuando el problema se plantea como si requiriera una solución meramente "técnica", esto es, una que permita eliminar aparentes contraejemplos mediante refinamientos más o menos ingeniosos de la tesis inicial -que podría ser, por ejemplo, la tesis de que los portadores de verdad son oracionescaso. $\mathrm{Si}$, en cambio, suponemos que la verdad es una propiedad y preguntamos cuáles son las entidades que tienen esa propiedad, estamos planteando el problema de los portadores de verdad, y cualquier manera de contribuir a su discusión requerirá "la introducción de nuevas consideraciones en la filosoffa del lenguaje y la metafísica" (p. 75). Platts, 1979, señala con razón que el problema de los portadores de verdad no se puede resolver mediante el análisis del lenguaje ordinario. En efecto, la pregunta correspondiente no está implícitamente respondida en dicho lenguaje; la gente común atribuye verdad a lo que se dice sin pronunciarse en modo alguno sobre la naturaleza o el status ontológico de lo que se dice: "El discurso ordinario sugiere que la gente dice cosas y que atribuye verdad a lo que se dijo. Pero ésta difícilmente es una base empírica clara sobre la cual construir una teoria. Aquil, más que en ninguna otra parte, se revela el carácter empobrecido y fraudulento de ese fenómeno pasajero que es la "filosofía del lenguaje ordinario" " (p. 64).

2 La expresión "portadores de verdad" es obviamente incómoda. Moretti (1984) propone "veritables", y yo mismo pensé alguna vez en "aletéforos" -que, sin duda, suena estrafalario, pero seguramente no más que "semáforo" (= "portador de la señal") en su origen-; sin embargo, tengo ahora la impresión de que ninguno de estos neologismos contribuiría sustancialmente a una mayor comodidad en el tratamiento del tema. 
Habermas descarta rápidamente a las oraciones, sin distinguir entre oraciones-tipo y oraciones-caso (aunque la última parte de lo que dice al respecto sólo puede ser verdadera de las primeras):

Escasas perspectivas de éxito son las que ofrece la tentativa de escoger una determinada clase de oraciones como aquello a lo que podemos atribuir verdad o falsedad. Pues oraciones de distintas lenguas o diversas oraciones de la misma lengua pueden reflejar el mismo estado de cosas, mientras que las mismas oraciones cuando aparecen en diversos contextos del habla, pueden reflejar también diversos estados de cosas. [1972, p. 113]

Que la misma oración pueda "reflejar" (describir, expresar) distintos estados de cosas implica que su valor de verdad puede cambiar, ya que algunos de esos estados pueden ser reales -dicho de otro modo, pueden ser "hechos"- y otros, meramente posibles, con lo cual la oración violaría el desideratum 1), que Habermas suscribe de modo explícito en una versión reforzada que enseguida consideraremos. Pero, ¿qué tiene de malo que distintas oraciones puedan describir el mismo estado de cosas? Habermas parece estar presuponiendo una variante de la teorfa correspondentista de la verdad que establece una correspondencia biunivoca entre portadores de verdad verdaderos y estados de cosas reales, y, como veremos, parece creer que las proposiciones pueden desempeñar el primero de esos papeles (y tal vez, curiosamente, también el segundo). Sin embargo, esta exigencia, bajo el supuesto de que las proposiciones son las portadoras de la verdad, resulta incompatible con el desideratum 1). Debido a lo maleable que es la noción de estado de cosas, podemos conseguir que una proposición describa siempre el mismo estado de cosas; podemos sostener que, por ejemplo, la proposición expresada por la oración "El actual presidente de la República es abogado" describe, de modo permanente o atemporal, un estado de cosas que consiste en que el presidente de los argentinos - cualesquiera que fueren las circunstancias de tiempo y persona- sea abogado (lo que por otra parte es muy probable, ya que, como dijo César Fernández Moreno, pocos argentinos no lo son). Pero es obvio que, en ese caso, la proposición será a veces verdadera y a veces falsa. Otra maniobra para conseguir que cada proposición describa exactamente un estado de cosas, impidiendo al mismo tiempo que su valor de verdad cambie, consiste en hacer tan estricto el criterio de identidad para proposiciones como para que cualquier cambio en el estado de cosas implique un cambio de proposición; pero esta maniobra establece una correspondencia biunívoca entre proposiciones y oraciones-caso, con lo cual pierde credibilidad, por razones de economía ontológica, la postulación de las primeras como purtadoras de verdad.

Hemos sugerido la simpatía de Habermas por las proposiciones; no resulta sorprendente, pues, que también a las afirmaciones las haga a un lado sin vacilar: 
Pues las afirmaciones representan emisiones o episodios lingüísticos datables, mientras que, manifiestamente, la verdad exige invariabilidad y posee, por tanto, un carácter no episódico. [p. 114]

Señalemos, en primer lugar, que la palabra "afirmación" se usa aquí para referirse al acto de afirmar y no a su contenido; a esto último, es decir, a lo afirmado, Habermas lo identifica — sin argumentar a favor de tal identificación-con las proposiciones, que llama también enunciados (Aussagen), y que son para él los portadores de la verdad: "Verdaderos o falsos llamamos a los enunciados en atención a los estados de cosas que en esos enunciados se reflejan o expresan" (ibid.). Esto último es una variante borrosa de la definición correspondentista de la verdad. Volveremos enseguida sobre la cuestión de qué es la verdad para Habermas, pero antes queremos decir algo acerca de cómo parece entender la "invariabilidad de la verdad" en el pasaje que citamos un poco más arriba.

Parece entenderla en un doble sentido según el cual es necesario no sólo que no cambie el valor de verdad de los portadores de verdad, según lo pide el desideratum 1), sino también que dichos portadores sean eternos o atemporales, y no "episódicos" o efímeros. Tal vez Habermas confunda estas dos exigencias y crea estar presentando la primera cuando plantea la segunda, cuya verosimilitud es prima facie dudosa. El carácter absoluto de la verdad, o su invariabilidad, no requiere que los portadores de verdad sean inalterables; ni siquiera requiere que haya portadores de verdad; lo que requiere es que, si los hay, sus valores de verdad sean inalterables.

Por otra parte, pocas líneas después de desechar a las afirmaciones como posibles portadores de verdad debido a su carácter "episódico", Habermas suscribe la idea de que un enunciado es verdadero (o falso) sólo si alguien lo afirma, con lo cual los enunciados, qua portadores de verdad, terminan siendo tan efímeros como las afirmaciones. Dice, en efecto, Habermas:

Sin embargo, no podemos privar a los enunciados de toda fuerza asertórica. [...] Un enunciado recibe fuerza asertórica por su inserción en un acto de habla, por la circunstancia, pues, de que alguien pueda afirmar ese enunciado. [...] la verdad es una pretensión de validez que vinculamos a los enunciados al afirmarlos. [Ibid.]

Es indudable que los argumentos de Habermas en favor de las proposiciones o enunciados son el resultado de un tratamiento breve y superficial del tema, y parecería que hasta incurren en alguna confusión de grosor no despreciable. Por otra parte, aun cuando se mejoraran sustancialmente esos argumentos, es sumamente dudoso que los esfuerzos destinados a probar 
que los portadores de verdad tienen que ser las proposiciones puedan tener un éxito completo. ${ }^{3}$

\section{III}

Los portadores de la verdad son, entonces, las proposiciones afirmadas. Las afirmaciones son actos de habla constatativos; afirmar es el tipo fundamental de tales actos, que incluyen también describir, narrar, exponer, explicar, predecir. Las afirmaciones mismas no son ni verdaderas ni falsas; están justificadas o no lo están. Afirmar algo es plantear la pretensión de que lo afirmado es verdadero: si se tiene razón, la pretensión está justificada; en caso contrario, no lo está. Las pretensiones de validez - uno de cuyos subconjuntos es el de las pretensiones de verdad- pueden ser cuestionadas, y en tal caso es posible asimismo defenderlas mediante argumentos (defenderlas "discursivamente", dice a veces Habermas, que usa "discurso" como sinónimo o abreviatura de "discurso argumentativo"). Como resultado de este proceso, las pretensiones de validez pueden ser finalmente reconocidas o rechazadas; si terminan por ser reconocidas y eso no se debe a ninguna coacción, ignorancia o engaño sino exclusivamente a la fuerza del mejor argumento, entonces están justificadas. Cuando la pretensión de validez justificada es de las que planteamos al hacer una afirmación -esto es, cuando se trata de una pretensión de verdad-, la proposición afirmada es verdadera.

Llamamos verdad a la pretensión de validez que vinculamos con los actos de habla constatativos. Un enunciado es verdadero cuando está justificada la pretensión de validez de los actos de habla con los que, haciendo uso de oraciones, afirmamos ese enunciado [p. 120]

Se dijo antes, sin embargo, que un enunciado es verdadero si describe un estado de cosas real. Ahora se dice que lo es si está justificada la pretensión asociada al acto que lo afirma. Es obvio que no se trata de la misma definición: la primera es una definición correspondentista, mientras que la segunda es pragmatista (no en el sentido de que identifique lo verdadero con lo útil o algo por el estilo, sino en el sentido de que relaciona la verdad con los hablantes). Tal vez Habermas crea que son definiciones coextensivas, esto es, que determinan el mismo conjunto de enunciados verdaderos; pero ni

3 Platts, 1979, aunque no atribuye importancia al problema (véase la nota 1), recuerda que "en el mejor de los casos las proposiciones son, como nos enseño Quine, cosas dudosas" (p. 65), y concluye "que las oraciones, con las relativizaciones adecuadas, son portadoras de verdad" (p. 67). Moretti, 1984, constituye una defensa eficaz de las oraciones contra reparos mucho más elaborados que los de Habermas; y Orayen, 1989, fundamenta minuciosamente la tesis de que las oraciones-caso con valor de verdad —que él llama "enunciados" — son los mejores candidatos a portadores de verdad en la teoría lógica del lenguaje ordinario. 
siquiera esto ocurre: hay enunciados que sólo pueden defenderse mediante argumentos si son falsos, como "No existe nada" o "No hay hablantes" o "No hay discurso argumentativo sino sólo retórica persuasiva", pero esto no implica que no puedan ser verdaderos en sentido correspondentista, esto es, que no pueda darse el estado de cosas que describen.

Habermas suscribe una de las objeciones tradicionales contra la teoría correspondentista, a saber, que confunde hechos y objetos. Los objetos están "en el mundo", los hechos no; es por eso por lo que puedo fotografiar la mesa pero no el hecho de que sea marrón. Los objetos son aquello acerca de lo cual hacemos afirmaciones, o aquello sobre lo cual versan los enunciados. Un hecho es, en cambio, lo afirmado por una afirmación justificada, o sea, lo que hace verdadero a un enunciado; por eso se dice que los enunciados describen (expresan, reflejan) hechos. Experimento (veo, oigo) objetos, pero no hechos; los hechos los afirmo. Hechos y objetos tienen, pues, distinto status ontológico: los objetos de nuestra experiencia están en el mundo, pero no podemos decir lo mismo de los hechos. La teoría correspondentista, al decir que son verdaderos los enunciados que corresponden a hechos, necesita que los correlatos de los enunciados, los hechos, estén en el mundo como lo están los objetos. Como esto no puede ser, la teoría está mal. Formulada con otras palabras, la objeción dice lo siguiente: los hechos están del lado del lenguaje, no del lado del mundo; el correspondentismo, al postular una correspondencia entre hechos y enunciados verdaderos, no puede rebasar el ámbito del lenguaje, cosa que, sin embargo, debería hacer para resultar aceptable.

El obstáculo no parece insuperable. En lo que concierne al "núcleo duro" de la teoría correspondentista - y no al "cinturón de seguridad" de cualquiera de sus variantes particulares-, las definiciones correspondentistas de la verdad no necesitan hacer referencia a hechos, como no la hace, por ejemplo, la siguiente formulación: "Un enunciado es verdadero si dice que las cosas son así y asá, y las cosas son así y asá". ${ }^{4}$ Podría alegarse que esta última definición hace referencia a hechos aunque no figure en ella la palabra "hecho". Pero no es necesariamente así. Como lo indica Platts (1979),

en la teoría de Tarski la verdad se define en términos de la satisfacción. Una teoría que invoca la satisfacción cubre la mayor parte de la caracterización de las teorías de la correspondencia. Es una relación entre portadores de verdad y entidades reales y es una relación estructural del tipo deseado: concierne a partes de los portadores de verdad, a las funciones oracionales y a elementos de la realidad, a saber, las secuencias de objetos. El papel de las secuencias es la

4 Algunos llaman a esto una "teoría realista de la verdad" y dan otro sentido a la expresión "teoría de la correspondencia": "El sello de las teorias de la correspondencia, tal como entiendo la expresión, es la construcción de relaciones detalladas de correspondencia, estructurales y convencionales, entre las partes de los portadores de verdad y las partes de las entidades en el mundo que determinan la verdad" (Platts, 1979, p. 58). 
razón de la cláusula "la mayor parte" en la penúltima oración: pues es posible sostener la teoría de Tarski sin aceptar una ontología de hechos, estados de cosas o lo que fuere [pp. 58-9]

en nuestra teoría las oraciones son portadoras de verdad, con funciones oracionales como los ítemes satisfechos. La satisfacción definida recursivamente es la relación, las secuencias de objetos son los satisfactores. [...] los hechos, los estados de cosas [...] no figuran en absoluto. [p. 60]

También lo señala Moretti (1986) en el siguiente pasaje (que resume una de las conclusiones del capítulo V, pp. 77-158, donde puede encontrarse su fundamentación pormenorizada):

No se necesita elaborar una noción de hecho que sea independiente de la idea de oración verdadera; el término objetivo de la relación son las entidades in. dividuales y sus clases naturales. La correspondencia ya no tiene que ser copia o función biunívoca o isomorfismo estructural o primitivo teórico, sino que resulta, formalmente, la satisfacción de una función proposicional por una secuencia de objetos y su aspecto material — por decir así-concerniente al nexo lenguaje-realidad viene dado por la relación referencial, cuya explicación en términos causal-históricos garantiza su objetividad y también permite la de la realidad referida. [p. 158]

Habermas podría objetar que también esto -grosso modo, el concebir la verdad como una relación entre enunciados y objetos, y no como una entre enunciados y hechos-es confundir hechos y objetos, ya que son los hechos, y no los objetos, los que hacen verdaderos a los enunciados. Pero, frente a una presunta prueba de que la verdad puede ser entendida como una relación entre enunciados y objetos, semejante reproche sería una petición de principio.

IV

La respuesta de Habermas a la pregunta "¿Qué es la verdad?" combina a) la tesis de que un enunciado es verdadero si describe un "hecho" - esto es, un estado de cosas real, y no uno meramente posible - con b) la tesis de que, en cierto sentido, los hechos no son "extralingüísticos". Con respecto a lo primero, la teoría correspondentista (tal como él la entiende)

descansa en una observación correcta. Si los enunciados "reflejan" hechos y no se limitan simplemente a fingirlos o a inventarlos, entonces tales "hechos" tienen que estar dados de alguna manera; y precisamente ésta es la propiedad que poseen los objetos "reales", es decir, los objetos de la experiencia, los cuales "son algo en el mundo". Los enunciados han de ajustarse a los hechos y no los hechos a los enunciados. [p. 118; todas las comillas son de Habermas.] 
Tropezamos, entonces, con una dificultad: para ser verdaderos, los enunciados tienen que ajustarse a los hechos, pero los hechos no son algo que esté en el mundo, y parece necesario, al menos en principio, que lo sean para que los enunciados puedan ajustarse a ellos. Habermas procura superar esta dificultad apelando a la distinción entre discursos y acciones: "Esta dificultad desaparece - dice inmediatamente a continuación del último pasaje que citamos- si tenemos en cuenta que los 'hechos' sólo advienen al lenguaje en el ámbito de comunicación que es el discurso" (ibid.). 'La "acción" es el ámbito de comunicación en el que suponemos tácitamente las pretensiones de validez implicadas por las emisiones (entre las cuales están las afirmaciones, que implican pretensiones de verdad) para intercambiar información sobre objetos de la experiencia. El "discurso" es la forma de comunicación que se caracteriza por la argumentación, en la que se "tematizan" las pretensiones de validez que han sido problematizadas. Los discursos exigen que se suspendan las coacciones de la acción y quede neutralizada cualquier motivación que no sea la disposición cooperativa a entenderse; exigen también, en segundo lugar, que se "virtualicen" las pretensiones de validez y se deje en suspenso la cuestión de la existencia de objetos de la experiencia, y se consideren tanto los hechos como las normas desde el punto de vista de su posible existencia o legitimidad. Los hechos sólo hacen su aparición en el discurso cuando se problematiza la pretensión de validez asociada a los enunciados, es decir, cuando se pone en tela de juicio una pretensión de verdad. En los contextos de acción transmitimos informaciones sobre objetos de la experiencia; es cierto que el contenido de la información se apoya en hechos, pero sólo cuando se la pone en duda y se discute ese contenido hablamos de "hechos" que al menos un proponente afirma y al menos un oponente cuestiona. Que un semáforo esté en rojo es, en el contexto del tránsito automovilístico, una información; se puede decir también que es un hecho, pero sólo lo decimos cuando, después de un accidente, hay que aclarar el estado de cosas que consiste en que aquel semáforo estaba en rojo. Estamos, según Habermas (p. 119), ante afirmaciones de la misma forma gramatical pero que significan cosas distintas: en el contexto de acción, la afirmación desempeña el papel de una información acerca de una experiencia con objetos; en el discurso cumple la función de un enunciado cuya pretensión de validez ha sido problematizada. El mismo acto de habla expresa en el primer caso una experiencia, en el segundo un pensamiento (Gedanke) verdadero o falso. Los estados de cosas son el contenido proposicional de afirmaciones cuya verdad ha sido cuestionada. Cuando definimos los hechos como estados de cosas existentes, no nos estamos refiriendo a la existencia de objetos sino a la verdad de proposiciones, aunque estamos suponiendo la existencia de objetos de los cuales predicamos algo. El sentido de "hecho" o "estado de cosas" sólo puede aclararse 
por referencia a discursos en los que examinamos la pretensión de validez de las afirmaciones.

Es cierto que en una argumentación puede apelarse a experiencias. Pero la apelación a la experiencia depende de interpretaciones que sólo en el discurso pueden acreditar su validez. Las pretensiones de verdad pueden basarse en la experiencia, pero la experiencia no puede fundamentarlas. Las pretensiones de verdad sólo pueden defenderse mediante argumentos. "La idea de verdad sólo puede desarrollarse por referencia a la defensa discursiva de pretensiones de validez" (p. 120). Las informaciones son confiables o no lo son; su confiabilidad se mide por la probabilidad de que se cumplan los pronósticos que de ellas se derivan. La verdad no es una propiedad de las informaciones sino de los enunciados, y no se mide por la probabilidad de que se cumplan pronósticos sino por la posibilidad de defender discursivamente las pretensiones de validez de las afirmaciones.

Llamamos verdaderos a los enunciados que podemos fundamentar. El sentido de la verdad, implicado en la pragmática de las afirmaciones, sólo puede aclararse suficientemente si podemos a su vez aclarar qué significa "defensa discursiva" [discursive Einlösung] de pretensiones de validez fundadas en la experiencia. Precisamente esto es el fin de una teoría consensual de la verdad. [Ibid.]

Según esta teoria, sólo puedo atribuir, mediante oraciones, un predicado a un objeto si cualquiera que pudiera discutir conmigo atribuiría el mismo predicado al mismo objeto; para distinguir los enunciados verdaderos de los falsos, me remito al juicio de todos aquellos con los que contrafácticamente podría discutir si mi vida fuera coextensiva con la historia del género humano. "La condición para la verdad de los enunciados es el potencial asentimiento de todos los demás. [... L La verdad de una proposición significa la promesa de alcanzar un consenso racional sobre lo dicho" (p. 121).

\section{V}

Al considerar las tesis de Habermas sobre el (nulo) papel de la experiencia en la justificación de afirmaciones, inevitablemente acuden a la memoria las opiniones de Popper sobre dicho tema (que se examinan en Comesaña,

5 Nos apartamos en un punto de la esmerada versión de Manuel Jiménez Redondo, que traduce einlösen como "resolver" o "desempeñar", pero esto último en el sentido de rescatar algo pignorado (sacarlo del empeño). Cuando una pretensión de validez es problematizada, pasa a encontrarse en una situación comprometida, análoga a la de algo pignorado o empeñado, y sólo en el discurso, esto es, sólo mediante argumentos, se puede tratar de rescatarla o "des-empeñarla". Semejante uso de "desempeñar" resulta inc $\delta$ modo y engañoso; parecen preferibles "defender" y "reivindicar", y éstos son los términos que emplearemos, incluso en las citas textuales. 
1991), debido a que entre ambas concepciones de la "base empírica" existen notorios puntos de contacto - aunque también, por cierto, diferencias. No es casual que el mejor expositor de Habermas, Thomas McCarthy (1978, p. 349), invoque a Popper en relación con este tema. Después de citar el siguiente pasaje de Habermas:

Al afirmar un estado de cosas no estoy afirmando una experiencia [...] Puedo, a lo sumo, aducir como datos experiencias estructuralmente análogas para fundamentar la pretensión de verdad planteada con el enunciado que afirmo. [Habermas, 1968, p. 389]

MacCarthy agrega: "O como dice Popper: 'Sólo en el curso de la discusión crítica se apela a la observación como a un testigo'"(1973, p. 348).

Hay, en efecto, notables coincidencias entre la concepción popperiana de la base empírica y la de Habermas, lo suficientemente amplias como para que las principales objeciones que se le han formulado a la primera alcancen también a la última. También hay grandes diferencias entre las ideas de ambos autores, especialmente en lo que concierne al tema central de este trabajo. En su Lógica de la investigación, publicada en 1934, Popper no quiso hablar de la verdad para no correr el riesgo de verse envuelto en paradojas; pero posteriormente, desde que Tarski lo convenció de que ese peligro había dejado de existir, nunca dejó de profesar un correspondentismo extremo y entusiasta. En efecto, no sólo suscribe la idea de que la verdad es correspondencia con los hechos sino que además está convencido de que, para que pueda serlo, es necesario que esos hechos tengan lugar en un mundo externo; dicho de otro modo, Popper agrega al correspondentismo la tesis de que dicha teoría de la verdad implica el realismo metafísico (tesis que seguramente es falsa; cfr. al respecto Haack, 1978, y Moretti, 1986). Habermas, en cambio (aunque parece asignar algún lugar a la verdad correspondentista en su teoría - cuestión sobre la que tendremos que volver), se inclina, como hemos visto, por una teoría consensual de la verdad. Sin embargo, pese a esta importante diferencia en cuanto a teoría de la verdad, su concepción de la base empírica - esto es, del papel que desempeña la experiencia en la aceptación de enunciados- presenta, como afirmamos al comienzo de este párrafo, notables coincidencias con la de Popper.

En ambos casos, la ciencia, y el conocimiento en general, quedan desconectados de la experiencia; y en ambos casos por la misma razón, a saber, porque los enunciados sólo pueden justificarse por medio de enunciados, y esto exclusivamente en el terreno de la "discusión crítica" (Popper), o porque las pretensiones de verdad sólo pueden defenderse por 
medio de argumentos, esto es, en el contexto del "discurso" (Habermas). ${ }^{6}$ Hay, sin embargo, una diferencia: para Popper los razonamientos o argumentos constan de enunciados o de oraciones; para Habermas, en cambio, que los enfoca desde un punto de vista "pragmático", constan de actos de habla constatativos -de afirmaciones. Pero esta diferencia no parece muy importante si se tiene en cuenta que Habermas establece una correspondencia biunívoca entre ambas cosas: una oración expresa una proposición, según él, si y sólo si alguien la usa o emite para hacer una afirmación. También la motivación principal para adoptar las ideas mencionadas acerca de la experiencia parece ser la misma en Popper y Habermas: ambos parecen aspirar, en efecto, a una certeza que, aunque seguramente es inalcanzable en general -cosa que ellos aparentan ignorar, a pesar de sus protestas de falibilismo-, se muestra especialmente esquiva en el terreno del conocimiento empírico.

La experiencia cae fuera de la "lógica de la ciencia" que a Popper le interesa y, también, de modo análogo, fuera de la "lógica del discurso" que interesa a Habermas. Las razones no son en este punto las mismas. Popper se desentiende simplemente de la experiencia debido a su carácter psicologico, mientras que Habermas esboza al respecto una teoría según la cual, en los contextos de acción y experiencia, los lenguajes naturales y los sistemas conceptuales asociados a ellos, "constituyen" los ámbitos objetales a los que después se van a referir los enunciados. Pero, a pesar de esta diferencia en las motivaciones, tanto Popper como Habermas excluyen a la experiencia del ámbito de la "lógica", que es el único en el que está presente la verdad, y niegan con ello que resulte pertinente con respecto a cuestiones de justificación.

Otro rasgo común que apunta en el mismo sentido es la tesis de que todos los enunciados, incluidos los que, por referirse a objetos físicos ordinarios, pueden razonablemente considerarse observacionales, como "Esto es un vaso de agua" -famoso ejemplo de Popper - o "Esta pelota es roja" (Habermas), contienen términos generales cuyo significado no puede agotarse en ninguna experiencia. $Y$ otro más es la idea de que, en lo que respecta a la, verdad y la justificación o aceptación racional de enunciados científicos (y, en general, cognoscitivos), los enunciados que importan no son ésos sino los legaliformes.

La tesis de que los factores psicológicos no tienen nada que ver con cuestiones de justificación es extremadamente contraintuitiva. Intuitivamente parece que una persona puede creer algo justificadamente y otra puede creer lo mismo sin justificación si sus creencias están causadas de modo diferente. Si un paciente cree que sus síntomas son psicosomáticos y no

6 Parte de la coincidencia consiste, como se ve, en que ambos apelan a "estrategias dial6gicas", como las llama Rabossi, 1993, que señala varias dificultades con que tropiezan los planteamientos de este tipo. 
indican ningún problema cardíaco grave porque eso le fue revelado en un sueño (tomo este ejemplo de Haack, 1991), y su médico cree lo mismo porque se lo sugieren los resultados de radiografías, electrocardiogramas, análisis de sangre, etc., uno se siente fuertemente inclinado a decir que la creencia del médico está justificada y la del paciente no. Haack elabora una teoría para explicar cómo las causas de las creencias pueden influir en su justificación. Dicha teoría merece sin duda un examen cuidadoso que, sin embargo, estaría fuera de lugar en el presente trabajo, donde sólo nos interesa retener la idea de que, contra Popper y Habermas, la experiencia tiene capacidad justificatoria. Como lo señalaron Bernays, 1964, y Ayer, 1974, entre otros, nuestras experiencias, al motivar la decisión de aceptar enunciados, nos dan un fundamento adecuado para hacerlo, aunque no los verifiquen de modo concluyente.

Apel (1987, § 4.3, pp. 82-98) —que también propone una teoría consensual de la verdad - critica la teoría habermasiana de la verdad, y en particular el papel asignado a la experiencia en la aceptación de enunciados, ${ }^{7}$ según lineamientos similares, aunque presentados con otra terminología: entre las afirmaciones no problematizadas del "mundo de la vida" y los enunciados defendidos mediante argumentos es necesario admitir algo intermedio, los "juicios perceptuales referidos al discurso" que se aceptan en virtud de la "evidencia fenoménica"; dicho de otro modo, los enunciados observacionales que se aceptan porque se está viendo que efectivamente ocurre lo que ellos dicen que ocurre, pero que, eso no obstante, son, en la terminología de Habermas, enunciados y no meramente informaciones. Si yo digo "Está lloviendo" y mi acompañante, después de mirar por la ventana, dice "Es verdad que está lloviendo", esta comprobación metalingüística no es redundante y lo que yo hice fue afirmar una proposición, pero una proposición que se acepta no debido al éxito de su defensa argumentativa, sino en virtud de los resultados de la experiencia. Si no se admite esto, se propone una teoría de la verdad exclusivamente coherentista. Es interesante notar en este contexto, dice Apel, que Habermas, al comparar el discurso teórico con el práctico (1972, p. 142),

en la columna "fundamentaciones" inserta inmediatamente, como correspondencia con "justificación" de preceptos/prohibiciones, la "explicación teórica" de "afirmaciones". Evidentemente, se pasa por alto la prueba de la existencia del estado de cosas fenomenal correspondiente al hecho afirmado, la cual debe preceder a cualquier posible explicación. [p. 87, n. 57]

7 Podría dudarse de que las ideas sobre dicho papel formen parte de algo razonablemente denominado "teoría de la verdad". Sin embargo, como lo señala Platts (1979, p. 23), esa expresion ha sido aplicada a ejercicios bastante dispares, y uno de ellos "es el intento de proveer una prueba o un conjunto de pruebas mediante las cuales puedan determinarse los valores de verdad de oraciones dadas" (ibid.). 
¿Cuál es, en definitiva, la definición que propone Habermas de la verdad? ¿Y cuál es su criterio para reconocerla? ¿Son dos cosas distintas la definición y el criterio, $o$, por el contrario, son una sola? La producción argumentativa de consenso, o su posibilidad, ies un criterio de verdad o es el significado de "verdadero", o es las dos cosas al mismo tiempo? Estas preguntas no son fáciles de responder porque Habermas muestra frente a ellas vacilaciones y cambios de idea. Cuando responde a la objeción de que las teorías pragmáticas de la verdad confunden significado y criterio, dice que tal objeción no afecta a su teoría, que no hace referencia "en modo alguno a métodos determinados de obtención de enunciados verdaderos" (1972, p. 139) —es decir, que no pretende suministrar criterios de verdad-, y que "pertenece a la naturaleza de las pretensiones de validez el poder justificarse, y aquello mediante lo que pueden justificarse es precisamente lo que constituye su significado" (ibid.; pero cito la traducción que hace Jiménez Redondo de este pasaje en McCarthy, 1978, p. 351). Quiere decir, entonces, que, hasta aquí, la (posibilidad de) producción argumentativa de consenso no es un criterio de verdad sino la definición de la verdad. Sin embargo, acto seguido, en respuesta a otra posible objeción, Habermas dice que un acuerdo contingente "no podría valer como criterio de verdad" y que "vale como criterio de verdad" el consenso fundado. Por si esto fuera poco, agrega:

Éste [el consenso fundado] vale como criterio de verdad, pero el significado de la verdad no consiste en la circunstancia de que se alcance un consenso, sino en que en todo momento $y$ en todas partes, con tal que entremos en un discurso, pueda llegarse a un consenso en condiciones que permitan calificar a ese consenso de consenso fundado. Verdad significa warranted assertibility. [ibid.]

¿Querrá decir Habermas con esto que la producción efectiva de consenso fundado es un criterio de verdad, mientras que la posibilidad de producir tal consenso es el significado o la definición de la verdad? No es nada seguro que quiera decir semejante cosa, cuya verosimilitud, por otra parte, está lejos de ser obvia.

En (1980), respondiendo a una objeción de J.B. Thompson, Habermas vuelve a ofrecernos un amplio abanico de posibilidades:

Lo que el oponente pone en cuestión es la pretensión que el proponente entabla a favor de su enunciado; a saber: que se cumplen las condiciones de la validez de "p". Esta pretensión de verdad que el proponente hace valer en favor de "p" no es idéntica, ciertamente, a la verdad o validez de " $p$ ": " $p$ " es verdadero si se cumplen las condiciones de verdad de " $p$ ". Pero hacer valer tal pretensión significa ofrecer como defensa en un juego argumentativo frente a oponentes 
la afirmación de que se cumplen las condiciones de verdad de "p". Ciertamente que lo uno no puede equipararse con lo otro. [p. 464]

Hasta aquí todo parece indicar que la verdad es correspondencia con los hechos, o como se lo quiera llamar, al margen de que los hechos sean extralingüísticos o no lo sean; y daría también la impresión de que la defensa argumentativa de los enunciados funciona como criterio de verdad. Sin embargo, sigue diciendo Habermas:

Pero el "quid" de la teoría discursiva de la verdad consiste en que trata de fundamentar por qué la pregunta acerca de qué significa que se cumplen las condiciones de verdad de "p", sólo puede responderse con la explicación de qué significa defender o fundamentar con argumentos la pretensión de que se cumplen las condiciones de verdad de " $\mathrm{p}$ ". Con ello queda sensiblemente relativizada la diferencia aparentemente clara entre la explicación del significado de "verdad" y la cuestión de los criterios con que decidir sobre la verdad de un enunciado. [Ibid.; todos los subrayados son de Habermas]

Parecería que pasamos ahora, sin solución de continuidad, a la idea de que la fundamentación argumentativa de pretensiones de verdad es a la vez definición y criterio de la verdad. Todo lo contrario; no es ninguna de las dos cosas:

La explicación del sentido procedimental de la defensa discursiva de pretensiones de validez no coincide ni con lo uno ni con lo otro. Así, la aclaración de los presupuestos comunicativos universales del discurso no ofrece ningún procedimiento suficientemente operacionalizado cuya observancia pudiera comprobarse como puede comprobarse la aplicación de un criterio. Los criterios de verdad pertenecen a un plano distinto que la idea de defensa de pretensiones de validez aclarada en términos de teoría del discurso [Ibid.; subrayado por Habermas].

En 1983 Habermas ratifica esto último al corregir la parte de su (1972) que examinamos un poco más arriba mediante el siguiente agregado:

hablar de criterio de verdad puede conducir a confusiones. La teoría consensual explica el significado del concepto de verdad, para lo cual recurre ciertamente a un procedimiento, pero no de hallazgo de la verdad, sino de defensa de pretensiones de verdad. [Ibid., n. 32]

Pero no ratifica el comienzo de la cita anterior, ya que ahora, nuevamente, la teoría consensual sí explica el significado de "verdad" recurriendo para ello al procedimiento mediante el cual se defienden las pretensiones de verdad. ¿Cuál es la mejor teoría de la verdad que uno puede adjudicarle a Habermas, ya que él mismo se muestra indeciso? Como cuestión exegética, 
parecería que, a pesar de las oscilaciones, predomina en los pasajes citados -y sin duda se manifiesta en el último de ellos- la tendencia a considerar la producción argumentativa de consenso, o su posibilidad, como el significado de "verdadero". No como las dos cosas a la vez — significado y criterio-, ya que la respuesta de Habermas a la objeción de que las teorías pragmatistas las confunden es que su teoría no pretende suministrar ningún criterio. También puede responderse, según Haack (1978, p. 110), que no se trata de una confusión sino de una identificación deliberada, ya que, para algunos pragmatistas, el significado de un término se da al suministrar criterios para su aplicación. ${ }^{8}$ Habermas opta por la otra variante, que enfrenta una dificultad adicional: si el consenso fundado es sólo la definición, ¿cuál es el criterio? No disponer de un criterio es uno de los reproches que normalmente se le hacen al correspondentismo, aunque hay que reconocer que no lo hemos encontrado en Habermas. Pero hay otra dificultad más grave: como definición, la teoría correspondentista de la verdad tiene ventajas sobre sus rivales que la hacen insustituible, ${ }^{9}$ y Habermas parece aceptar esto, ya que reiteradamente dice que un enunciado es verdadero si describe un hecho y otras cosas en la misma línea. Pero esto es, desde luego; incompatible con la idea de que la verdad es la (posibilidad de) producción argumentativa de consenso, que, bajo tal supuesto correspondentista, revelaría realmente una confusión entre significado y criterio. Ésta es también la opinión de MacCarthy (1978, pp. 351-2). Habermas podría defenderse -dice MacCarthy - alegando que, desde un punto de vista pragmático, "verdadero" no se predica de los enunciados sino de las pretensiones que se plantean al afirmarlos, y el significado de una pretensión tiene que analizarse en términos del modo en que se la puede justificar. "Esto puede ser algo más plausible [sic] —agrega-, pero ciertamente no es obvio" (p. 352). Y no persigue esa línea por entender que la teoría habermasiana de la verdad no necesita complicarse la vida sosteniendo que ése es el significado de la verdad. La versión que aparece con más frecuencia en Habermas es, según él, que el consenso racional es el criterio de verdad. Es posible conceder que las pretensiones de verdad tienen que ser justificadas discursivamente

8 Por eso es injusta, según ella, la acusación de Russell de que los pragmatistas confunden definición y criterio, ya que una identificación deliberada no puede ser una confusión. Parecería que la cuestión es verbal, y que lo importante es si la identificación es acertada o errónea, independientemente de que se la llame "confusión" o se opte por no hacerlo.

9 Esas ventajas son a) que coincide con las intuiciones de cualquiera: todos somos espontáneamente correspondentistas -aunque en la mayoría de los casos se necesita un "hábil interrogatorio" para que eso se ponga de manifiesto-, y b) que es "autosuficiente", mientras que sus rivales parecen tener necesidad de apoyarse en ella. Incluso alguien que propone una teoría consensual de la verdad, como Apel (1987), parece admitir estas dos ventajas cuando dice que "la teoría realista de la verdad como correspondencia no es sólo la intuición básica natural respecto a la verdad de los enunciados, sino que está presupuesta también por todas las teorías de la verdad como su condición necesaria" (p. 44). 
sin admitir que esto es lo que se quiere decir al decir que un enunciado es verdadero. "Y esto parece bastar para lo que Habermas pretende: que las pretensiones de verdad apuntan intrínsecamente a la posibilidad de un consenso racional" (ibid.).

Pero si la correspondencia con los hechos es la definición y el consenso racional el criterio - dicho de otro modo, si suscribimos un popperianismo levemente modificado-, sigue en pie el problema de que esto último no parece ser cierto en lo concerniente a los enunciados observacionales. Y si se hiciera una concesión más y se le reconociera capacidad justificatoria a la experiencia, las ideas de Habermas sobre el particular se tornarían extremadamente razonables, pero pasarían también a no tener la más mínima originalidad. En efecto, la idea de que a) un enunciado es verdadero si ocurre lo que ese enunciado dice que ocurre, y de que b) eso se averigua, $b_{1}$ ) en el caso de los enunciados observacionales, observando, y $b_{2}$ ) en todos los demás casos, argumentando, es, desde Aristóteles, la teoría de la verdad más difundida entre quienes "tematizan" el asunto.

\section{BIBLIOGRAFIA}

Apel, Karl-Otto, 1987, "Fallibilismus, Konsenstheorie der Wahrheit und Letzbegründung", en Philosophie und Begründung, Suhrkamp, Francfort. [Versión castellana de Norberto Smilg, "Falibilismo, teoría consensual de la verdad y fundamentación última", en id., Teoría de la verdad y ética del discurso, Paidós/ICE-UAB, Barcelona, 1991.]

Ayer, Alfred J., 1974, "Truth, Verification and Verisimilitude", en Paul Arthur Schilpp (comp.), The Philosophy of Karl Popper, 2 vols., Open Court, La Salle, 1974.

Bernays, Paul, 1964, "Reflections on Karl Popper's Epistemology", en Mario Bunge (comp.), The Critical Approach to Science and Philosophy, Free Press, Nueva York, 1964.

Comesaña, Manuel E., 1991, "Popper: experiencia y enunciados básicos", Análisis Filosófico, vol. XI, no. 2, pp. 141-151.

Haack, Susan, 1978, Philosophy of Logics, Cambridge University Press. [Versión castellana de Amador Antón con la colaboración de Teresa Orduña, Filosofía de las lógicas, Cátedra, Madrid, 1991.]

—, 1991, "What is 'the Problem of Empirical Basis' and Does Johnny Wideawake Solve It?", British Journal for the Philosophy of Science, no. 42, pp. 369-389.

Habermas, Jürgen, 1968, Erkenntnis und Interesse, Francfort, 1968. [Versión castellana, Conocimiento e interés, Madrid, 1982.]

—, 1972, "Wahrheitstheorien", en id., 1984, pp. 113-158.

—, 1980, "Réplica a objeciones", en id., 1984, pp. 399-477.

— 1984, Vorstudien und Ergänzungen zur Theorie des kommunicativen Handelns, Suhrkamp, Francfort. [Versión castellana de Manuel Jiménez Redondo, Teoría de la acción comunicativa: complementos y estudios previos, Cátedra, Madrid, 1989.] 
McCarthy, Thomas, 1978, The Critical Theory of Jürgen Habermas, Cambridge, Mass. [Versión castellana de Manuel Jiménez Redondo, La teoría crítica de Jürgen Habermas, Tecnos, Madrid, 1987.]

Moretti, Alberto, 1984, "Los objetos de predicación de verdad", Análisis Filosófico, vol. IV, no. 2, pp. 23-30.

_-, 1986, Desarrollo y estructura de la teoría realista de la verdad, tesis doctoral (inédita).

Orayen, Raúl, 1989, "Portadores de verdad", en Orayen, Lógica, significado y ontología, UNAM, México, 1989, cap. I, § 2, pp. 17-60.

Platts, Mark, 1979, Ways of Meaning: an Introduction to a Philosophy of Language, Routledge \& Kegan Paul, Londres. [Versión castellana de Cecilia Hidalgo y Eduardo Rabossi, revisada por Manuela Rius en colaboración con Antonio Zirión y el autor, Sendas del significado. Introducción a una filosofía del lenguaje, UNAM-FCE, México, 1992.]

__, 1985, "Acerca de 'Los portadores de verdad'", Análisis Filosófico, vol. V, no. 2, pp. 67-75.

Popper, Karl R., 1934, Logik der Forschung; traducción al inglés en id., 1959.

—, 1959, The Logic of Scientific Discovery, Hutchinson, Londres.

—, 1973, Objective Knowledge, Clarendon Press, Oxford.

Rabossi, Eduardo, 1993, "Estrategias dialógicas, universalidad y relativismo", en Oscar Nudler y Gregorio Klimovsky (comps.), La racionalidad en debate. Primer Coloquio Bariloche de Filosofía, CEAL, Buenos Aires, II, pp. 350-363. 